\title{
CROSSLINKED STYRENE/DIVINYLBENZENE NETWORK SYSTEMS
}

\author{
RICHARD H. WILEY \\ Department of Chemistry, Hunter College of the City University of New York \\ Park Avenue, New York 10021, USA
}

\begin{abstract}
Differences in properties of pure meta- and pure para-divinylbenzene crosslinked polystyrene and their sulphonated products have been correlated with probable network structural differences. The para-divinylbenzene copolymerizes more slowly than does the meta isomer to give a crosslinked copolymer which swells less, sulphonates less rapidly, and, when sulphonated, gives an ion exchanger which has lower selectivity. It is concluded, on the basis of copolymerization data, that the para crosslinked network is tighter and less uniform than that of the meta crosslinked network.

Techniques have been developed for the synthesis, separation and purification by gas chromatography, polymerization, and copolymerization of 99.5-99.9 per cent pure meta- and para-divinylbenzenes. Kinetics of the polymerization and copolymerization have been determined by radiocarbon techniques and computer analysis of high-conversion data. The preparation and sulphonation of the bead copolymers of styrene with the pure meta- and para-divinylbenzenes have been developed in detail and the exchange isotherms of the sulphonated beads have been evaluated.
\end{abstract}

\section{INTRODUCTION}

Most ion exchange resins are prepared from styrene/divinylbenzene crosslinked copolymers in bead form by processes that are not usually specified. These processes use for divinylbenzene the commercially available mixture of the meta- and para-divinylbenzene isomers. This mixture also contains varying amounts of other ingredients-chiefly meta- and para-ethylstyrenes. This ambiguously defined process leads to a network structure that is difficult to obtain reproducibly, and problems are thus added to the usual complications involved in studies of crosslinked polymer systems.

In our studies ${ }^{1-34}$ we have obtained data on the properties of pure metaand pure para-divinylbenzenes ${ }^{2,3,8,14,23,30}$; on the kinetics of their polymerization $^{12,26}$ and styrene copolymerization ${ }^{4,9,15,20,28,32,33}$; on the characteristics of the copolymers ${ }^{18,19,25,27}$ and their sulphonation ${ }^{11,13,16 \text {, }}$ 18,21,24; and some data on their sulphonated products $1,10,31,34$. Some related data have been obtained for ortho-divinylbenzene, 1,2,4- and 1,3,5trivinylbenzenes, and a series of divinyl compounds of the type $\mathrm{CH}_{2}=$ $\mathrm{CHC}_{6} \mathrm{H}_{4}-\mathrm{X}-\mathrm{C}_{6} \mathrm{H}_{4} \mathrm{CH}=\mathrm{CH}_{2}{ }^{1,6,17,20,22}$. 
The questions for which we have sought answers are: (1) what kind of data establish a difference between the meta and the para crosslinked systems and (2) what are the structural implications available from such differentiations? It is the extent to which we can provide answers to these questions that we wish to consider in this report.

\section{DIVINYLBENZENE MONOMERS}

The commercially available divinylbenzene is a complex mixture of 8-12 components. It is made by dehydrogenation of diethylbenzenes, in turn obtained by Friedel-Crafts alkylation of benzene with ethylene. The ethylbenzenes are a mixture of ortho, para and meta isomers. The ortho isomer is converted to naphthalene in the dehydrogenation and there is little to be gained in separating the ethylbenzenes prior to dehydrogenation, as the dehydrogenation catalyst re-equilibrates the isomeric mixture. One dehydrogenation process has been operated using an iodine catalyst which does not equilibrate the isomeric mixture, and during the time of its development relatively pure meta- and para-divinylbenzenes were available. Also, a process $^{23}$ for the separation of the divinyl isomers based on a Werner complex formation was at one time operated on a developmental basis. We have reported analytical gas chromatographic data for commercial divinylbenzene samples. Typical data are given in Figure 1. A complete listing of the components as identified by comparisons with retention times of known mixtures is given in Table 1 .

It is essential, for the purposes of establishing possible differences in the network systems obtained on copolymerization, that the pure meta and para isomers of divinylbenzene be separated and purified. The methods we have developed for this purpose are based on preparative gas chromatography

(a)

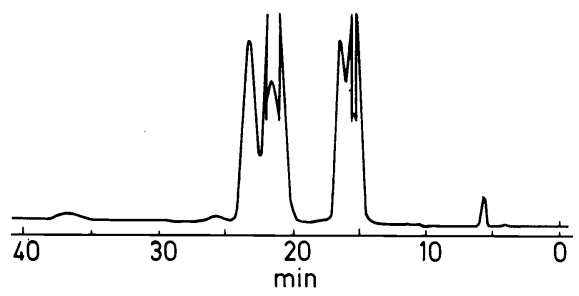

(b)

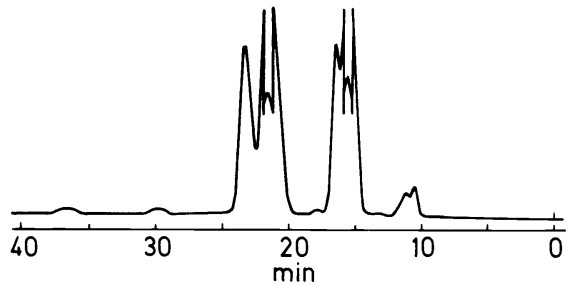

Figure 1. Chromatograms of commercial divinylbenzene: (a) sample I and (b) sample II of Table 1 
Table 1. Net retention times and relative retention ratios for components of commercial divinylbenzene samples

\begin{tabular}{|c|c|c|c|c|c|}
\hline \multirow[b]{2}{*}{$\begin{array}{l}\text { Peak } \\
\text { No. }^{a}\end{array}$} & \multirow[b]{2}{*}{ Component } & \multicolumn{4}{|c|}{ Observed net retention times, $\min$} \\
\hline & & $\begin{array}{c}\text { Known } \\
\text { compounds }\end{array}$ & $\begin{array}{l}\text { Mixture of } \\
\text { known } \\
\text { compounds }^{d}\end{array}$ & $\underset{\mathbf{I}^{e}}{\text { Sample }}$ & $\underset{\text { II }^{f}}{\text { Sample }}$ \\
\hline 1 & Air & 0 & 0 & 0 & 0 \\
\hline 2 & Ethylbenzene & 4.7 & 4.1 & 4.0 & - \\
\hline 3 & Styrene & - & 5.7 & 5.5 & - \\
\hline 4 & $m$-Diethylbenzene & 12.7 & 10.4 & 10.2 & 10.1 \\
\hline 5 & $p$-Diethylbenzene & 13.6 & 11.0 & 10.9 & 10.8 \\
\hline 6 & $m$-Ethylvinylbenzene & 18.1 & 15.1 & 14.9 & 15.1 \\
\hline 7 & $p$-Ethylvinylbenzene & 19.1 & 16.0 & 15.8 & 15.8 \\
\hline 8 & $o$-Divinylbenzene & 21.3 & 17.4 & 17.0 & 17.1 \\
\hline 9 & $m$-Divinylbenzene & 25.1 & 20.7 & 20.7 & 20.6 \\
\hline 10 & $p$-Divinylbenzene & 26.5 & 22.3 & 22.3 & 22.3 \\
\hline 11 & Unknown & - & - & 24.3 & 28.3 \\
\hline 12 & Naphthalene & - & 35.8 & 34.9 & 34.8 \\
\hline
\end{tabular}

\begin{tabular}{|c|c|c|c|c|c|}
\hline \multirow[b]{2}{*}{$\begin{array}{l}\text { Peak } \\
\text { No. }^{a}\end{array}$} & \multirow[b]{2}{*}{ Component } & \multicolumn{4}{|c|}{ Relative retention ratios ${ }^{b}$} \\
\hline & & $\begin{array}{c}\text { Known } \\
\text { compounds }\end{array}$ & $\begin{array}{l}\text { Mixture of } \\
\text { known } \\
\text { compounds }\end{array}$ & $\underset{I^{e}}{\text { Sample }}$ & $\underset{\text { II }^{f}}{\text { Sample }}$ \\
\hline 1 & Air & - & - & - & - \\
\hline 2 & Ethylbenzene & 0.187 & 0.198 & 0.193 & - \\
\hline 3 & Styrene & - & 0.277 & 0.266 & - \\
\hline 4 & $m$-Diethylbenzene & 0.506 & 0.503 & 0.493 & 0.491 \\
\hline 5 & $p$-Diethylbenzene & 0.541 & 0.531 & 0.527 & 0.525 \\
\hline 6 & $m$-Ethylvinylbenzene & 0.721 & 0.729 & 0.719 & 0.734 \\
\hline 7 & $p$-Ethylvinylbenzene & 0.760 & 0.772 & 0.764 & 0.766 \\
\hline 8 & $o$-Divinylbenzene & 0.849 & 0.841 & 0.822 & 0.830 \\
\hline 9 & $m$-Divinylbenzene & 1.00 & 1.00 & 1.00 & 1.00 \\
\hline 10 & $p$-Divinylbenzene & 1.06 & 1.08 & 1.08 & 1.08 \\
\hline 11 & Unknown & - & - & - & - \\
\hline 12 & Naphthalene & 1.68 & 1.73 & 1.68 & 1.69 \\
\hline
\end{tabular}

a In Figure 1 .

b $m$-Divinylbenzene as reference.

c Chromatographed singly, in sequence, on the same column, within $10 \mathrm{~h}$.

- Prepared from samples used for data in 'Component' column containing about the same relative amounts.

- Koppers Company, Lot No. 1992.

s Dow Chemical Company, Lot No. 12042.

of appropriate starting materials ${ }^{2,14}$. The pure (99.9 per cent) meta isomer is obtained by repetitive preparative gas chromatography of the commercial divinylbenzene mixture. Three passes through a 1 in $\times 6 \mathrm{~m}$ polypropyleneglycol (Ucon) on Chromosorb W column sufficed. Larger columns have been used in the initial separation. The pure ( 99.9 per cent) para isomer, being the lesser and trailing component and having a bothersome tendency to crystallize (m.pt, $35^{\circ} \mathrm{C}$ ), cannot be readily separated from the commercial mixed divinylbenzene isomers. It can be obtained in reasonable yield and fair purity by decarboxylation of $p$-phenylenediacrylic acid, in turn prepared 
from terephthaldehyde and malonic acid ${ }^{3}$. This material must be further purified, and to do so we customarily put it through a preparative GLC column (Bentone 34/Ucon on Chromosorb W) on which the para isomer precedes the meta and then finally distil from potassium hydroxide. The isomers thus purified gave reproducible kinetic data and bead copolymerization systems. NMR and mass spectral characteristics of the two pure isomers have been recorded ${ }^{8,30}$. Similar data have been obtained for 1,2,4and 1,3,5-trivinylbenzenes ${ }^{17}$.

\section{KINETICS OF THE POLYMERIZATION AND COPOLYMERIZATION OF META- AND PARA-DIVINYLBENZENES}

The kinetic data for the polymerization of pure meta- and pure paradivinylbenzenes up to the gelation point show that the conversion to polymer is directly proportional to time and to the square root of the initiator concentration. Data have been obtained for viscometric measurements in toluene ${ }^{9}$ and t-butylbenzene ${ }^{12}$ at 65 and $80^{\circ} \mathrm{C}$. Typical data are given in Figure 2 for the $65^{\circ} \mathrm{C}$, t-butylbenzene experiments. Activation energies

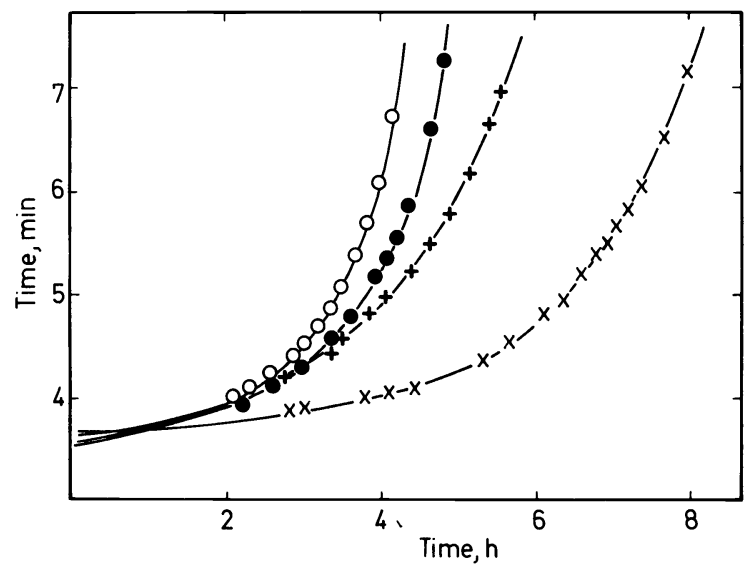

Figure 2. Rate of polymerization of divinyl isomers in t-butylbenzene at $65^{\circ} \mathrm{C}: \mathrm{O}, \mathrm{m}$-divinylbenzene; ๑, $2: 1 \mathrm{~m}$ :p-divinylbenzene; $\times$, $p$-divinylbenzene; + , commercial divinylbenzene. Abscissa, time of polymerization in hours; ordinate, efflux time in minutes

calculated from initial linear data are given in Table 2. Typical values are $23.3 \mathrm{kcal} / \mathrm{mol}$ ( $m e t a$ ) and $27.1 \mathrm{kcal} / \mathrm{mol}$ (para). The data from the dilatometric measurements ${ }^{26}$ are shown in Figure 3, and can be seen to be linear up to the gel point. Both data sets show that the meta isomer polymerizes more rapidly than does the para isomer. Gelation occurs at $90 \mathrm{~min}$ and 19.3 per cent conversion for the meta isomer; at $126 \mathrm{~min}$ and 16 per cent conversion for the para isomer. In other experiments it has been shown that the gel time is a linear function of the square root of the reciprocal of the initiator concentration and conversion at gel point is a linear function of the square root of 
the initiator concentration. The activation energies are normal for vinyl polymerizations and, up to the gel point, these divinyl monomers are behaving as typical monovinyl types with the para isomer the less rapidly polymerizing. It may be noted that the second vinyl group, whose reaction is required for crosslinking, should react as an alkyl-substituted styrene-

Table 2. Ratios of rate constants and activation energies for polymerization of divinylbenzene

(DVB) isomers at 65 and $80^{\circ} \mathrm{C}$

\begin{tabular}{|c|c|c|c|c|c|c|c|c|}
\hline \multirow[b]{2}{*}{$\begin{array}{l}\text { Efflux } \\
\text { time, } \\
\text { min }\end{array}$} & \multicolumn{2}{|c|}{$\begin{array}{c}\text { Commercial } \\
\text { DVB }^{a}\end{array}$} & \multicolumn{2}{|c|}{$m$-DVB } & \multicolumn{2}{|c|}{$2: 1 / m: p$-DVB } & \multicolumn{2}{|c|}{$p$-DVB } \\
\hline & $\begin{array}{l}\text { Rate } \\
\text { ratio }^{b}\end{array}$ & $\begin{array}{c}E_{A}, \\
\mathrm{kcal} / \\
\mathrm{mol}^{\mathrm{c}}\end{array}$ & $\begin{array}{l}\text { Rate } \\
\text { ratio }^{b}\end{array}$ & $\begin{array}{c}E_{A}, \\
\mathrm{kcal} / \\
\mathrm{mol}^{\mathrm{c}}\end{array}$ & $\begin{array}{l}\text { Rate } \\
\text { ratio }^{b}\end{array}$ & $\begin{array}{r}E_{A}, \\
\mathrm{kcal} / \\
\mathrm{mol}^{\mathrm{c}}\end{array}$ & $\begin{array}{l}\text { Rate } \\
\text { ratio }^{b}\end{array}$ & $\begin{array}{r}E_{A}, \\
\mathrm{kcal} / \\
\mathrm{mol}^{\mathrm{c}}\end{array}$ \\
\hline 4 & 2.57 & 14.9 & 3.09 & 17.8 & 3.09 & 17.8 & 3.72 & 20.8 \\
\hline 5 & 3.81 & 21.1 & 4.04 & 22.1 & 4.09 & 22.3 & 5.04 & 25.6 \\
\hline 6 & 4.23 & 22.8 & 4.29 & 23.0 & 4.36 & 23.3 & 5.29 & 26.3 \\
\hline 7 & 4.42 & 23.5 & 4.34 & 23.2 & 4.47 & 23.7 & 5.47 & 26.9 \\
\hline $\begin{array}{l}\text { Limiting } \\
\text { value }^{d}\end{array}$ & 4.52 & 23.8 & 4.35 & 23.3 & 4.48 & 23.7 & 5.54 & 27.1 \\
\hline
\end{tabular}

a Commercial divinylbenzene (Koppers).

b Ratio of polymerization times $t_{65^{\circ}} / t_{80^{\circ}}$ at stated efflux time.

c Activation energy calculated as $E_{A}=\left[R T_{1} T_{2} /\left(T_{2}-T_{1}\right)\right] \ln \left(t_{1} / t_{2}\right)$.

d Constant value that the ratios $t_{1} / t_{2}$ reach at gelation time, calculated by extrapolation.

Ratios of rate constants and activation energies for copolymerization of styrene-divinylbeznene isomers at 65 and $80^{\circ} \mathrm{C}$

\begin{tabular}{|c|c|c|c|c|c|c|c|c|}
\hline \multirow[b]{2}{*}{$\begin{array}{l}\text { Efflux } \\
\text { time, } \\
\text { min }\end{array}$} & \multicolumn{2}{|c|}{$\begin{array}{c}\text { Commercial } \\
\text { DVB }\end{array}$} & \multicolumn{2}{|c|}{$m$-DVB } & \multicolumn{2}{|c|}{$2: 1 / m: p$-DVB } & \multicolumn{2}{|c|}{$p$-DVB } \\
\hline & $\begin{array}{l}\text { Rate } \\
\text { ratio }\end{array}$ & $\begin{array}{c}E_{A}, \\
\mathrm{kcal} / \\
\mathrm{mol}\end{array}$ & $\begin{array}{l}\text { Rate } \\
\text { ratio }\end{array}$ & $\begin{array}{c}E_{A}, \\
\text { kcal/ } \\
\text { mol }\end{array}$ & $\begin{array}{l}\text { Rate } \\
\text { ratio }\end{array}$ & $\begin{array}{c}E_{A}, \\
\text { kcal/ } \\
\text { mol }\end{array}$ & $\begin{array}{l}\text { Rate } \\
\text { ratio }\end{array}$ & $\begin{array}{c}E_{A}, \\
\mathrm{kcal} / \\
\mathrm{mol}\end{array}$ \\
\hline 4 & 1.77 & 9.0 & 2.57 & 14.9 & 1.91 & 10.2 & 2.15 & 12.1 \\
\hline 5 & 2.16 & 12.2 & 2.58 & 15.0 & 2.45 & 14.2 & 2.75 & 16.0 \\
\hline 6 & 2.23 & 12.7 & 2.58 & 15.0 & 2.61 & 15.2 & 2.96 & 17.1 \\
\hline 7 & 2.27 & 13.0 & 2.59 & 15.0 & 2.67 & 15.5 & 3.05 & 17.6 \\
\hline $\begin{array}{c}\text { Limiting } \\
\text { value }\end{array}$ & 2.27 & 13.0 & 2.60 & 15.1 & 2.68 & 15.6 & 3.07 & 17.7 \\
\hline
\end{tabular}

corresponding roughly to an isopropylstyrene. We have shown that paraisopropylstyrene is a less reactive monomer than is styrene in copolymerization with styrene ${ }^{29}$.

The gelation characteristics of the two divinylbenzene isomers show distinctions which are apparently related to different crosslinking processes and network structures. Gelation time is a linear function of rate: i.e. the lower the rate, the longer the time to gelation, for both isomers. The rate is different for the two isomers. Significantly, however, the conversion at gelation also varies for the two isomers. At every rate level the more slowly polymerizing para isomer shows a lower conversion at gelation. This requires that less 


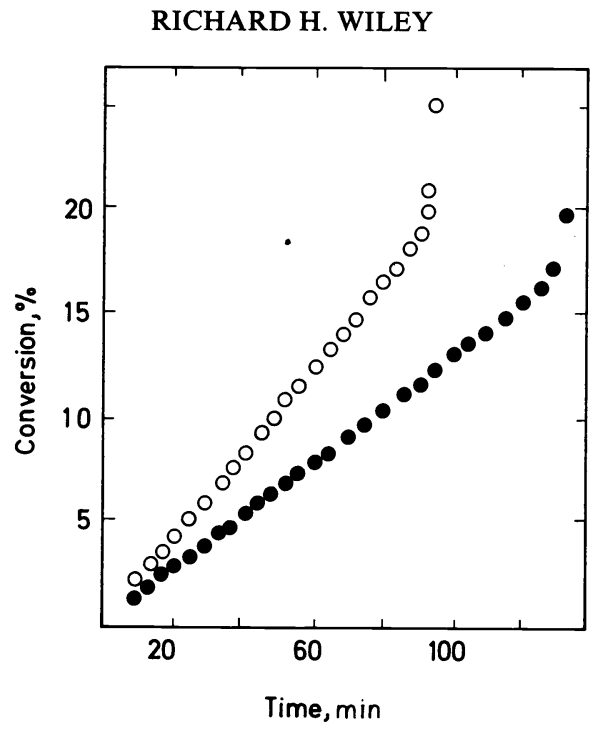

Figure 3. Polymerization of $m-(0)$ and $p-(+)$ divinylbenzenes in toluene at $70^{\circ} \mathrm{C}$. Concentration of divinylbenzene $2.28 \mathrm{~mol} / \mathrm{l}$; of dibenzoyl peroxide $7.29 \times 10^{-3} \mathrm{~mol} / \mathrm{l}$. Conversion versus polymerization time. Dilatometric data

monomer be incorporated into the para crosslinked structure at gelation and suggests that there is a greater build-up of molecular weight prior to crosslinking in the meta derived network. Alternatively, if the para derived structure is inherently less soluble (has a different solvent interaction relation), its structure must be inherently different.

The viscometric copolymerization kinetic rate data ${ }^{9,12}$ for the styrene/meta and para systems show similar, but less pronounced, differences. The styrene/ meta copolymerization is more rapid and has a lower activation energy

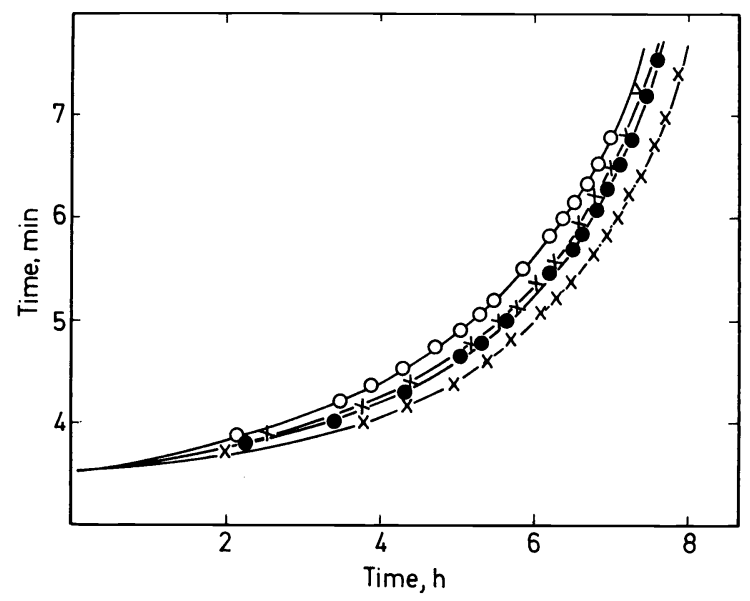

Figure 4. Rate of copolymerization of divinylbenzene isomers with styrene in t-butylbenzene at $65^{\circ} \mathrm{C}$; $\bigcirc$ styrene/m-divinylbenzene; $\bullet$ styrene/2:1-m:p-divinylbenzene; $\times$ styrene/p-divinylbenzene; + styrene/commercial divinylbenzene. Coordinates as in Figure 2 
$(15.1 \mathrm{kcal} / \mathrm{mol})$ than does the styrene/para copolymerization $(17.7 \mathrm{kcal} / \mathrm{mol})$. It is to be noted that the pronounced Trommsdorf ('gel') effects shown in the non-linear increase in rate with time is not customarily observed in styrene polymerizations. Data are shown in Figure 4.

\section{COPOLYMERIZATION REACTIVITY RATIO DATA FOR THE STYRENE/DIVINYLBENZENE SYSTEMS}

It is in the kinetic data for the copolymerization reactivity ratios that the most striking differences in the characteristics of the meta- and para-divinylbenzenes are observed. Using ${ }^{14} \mathrm{C}$-labelled styrene and radioactivity assay for the copolymer analysis ${ }^{4,5,15}$, we have determined the concentration of styrene in the instantaneous (actually low-yield) copolymers for each of the styrene/meta- and para-divinylbenzene pairs. The reactivity ratios have been evaluated in the usual fashion from the differential equation. The technique is reliable and has given some of the best data available for conventional monomer types ${ }^{5}$. Data for the styrene/glycol dimethacrylate pair $^{4}\left(r_{1}=0.4\right.$; $r_{2}=0.64:$ Figure 5) compare favourably with those for styrene/methyl

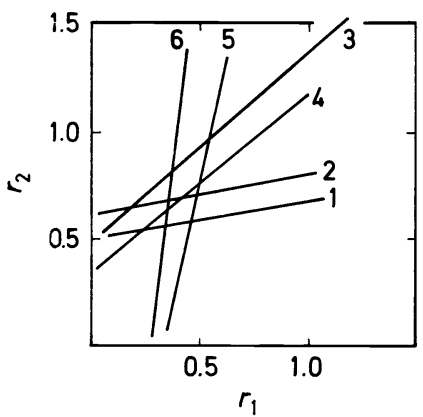

Figure 5. Graphical solution of the copolymerization equation for the styrene $\left(r_{1}=0.40\right)$ ethylene glycol dimethacrylate $\left(r_{2}=0.64\right)$ copolymerization.

methacrylate and are definitive. The 'instantaneous' (low-yield) copolymer would be expected to have involved no significant amount of the second vinyl group in a crosslinking reaction. The data for the styrene/metadivinylbenzene pair show intersects ${ }^{15}$ which, as required by theory, give unique solutions. There is, however, considerable variation in the values depending apparently on the extent of the 'low' yield actually taken and possibly the temperature of copolymerization. Thus: $r_{1}$ (styrene) $=0.6$; $r_{2}(m$-DVB $)=0.88$ at $80^{\circ} \mathrm{C}$ and $1.8-3.7$ per cent conversion (Figure 6); $r_{1}=1.27 ; r_{2}=1.08$ at $2.7-5$ per cent conversion (Figure 7); and $r_{1}=0.65$; $r_{2}=0.60$ at $60^{\circ} \mathrm{C}$ (Figure 8). The methyl methacrylate/meta-divinylbenzene pair shows values of $r_{1}=0.41, r_{2}=0.61$ (Figure 9$)^{28}$ very close to the values for styrene/methyl methacrylate and styrene/glycol dimethacrylate. In all of these experiments meta-divinylbenzene behaves more or less normally as a substituted styrene with no apparently inexplicable interference from the 


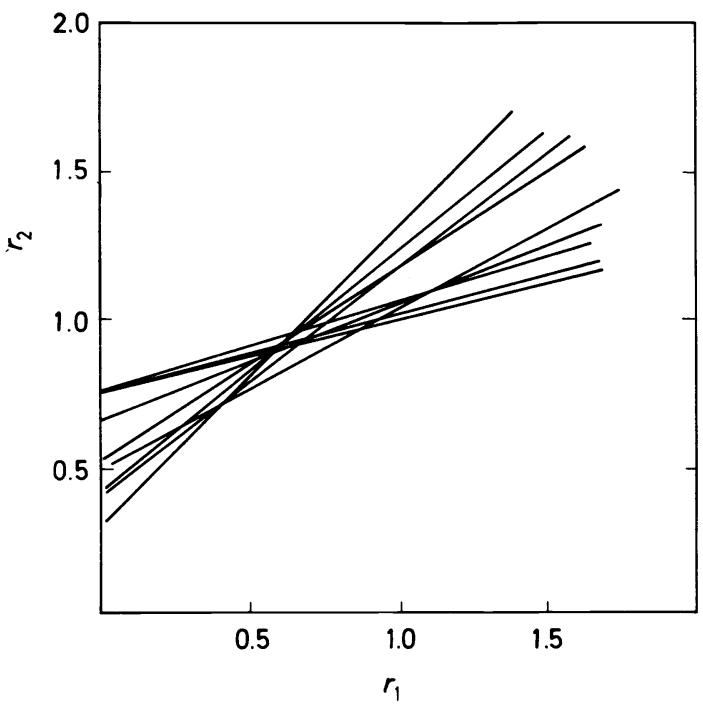

Figure 6. Intersect plot for the copolymerization of styrene $\left(r_{1}=0.6\right)$ with $m$-divinylbenzene $\left(r_{2}=0.88\right)$ at $80^{\circ} \mathrm{C}$ with benzoyl peroxide initiator. Conversion, $1.8-3.7 \%$

second vinyl substituent. The $Q$ - and $e$-values calculated for the styrene/ and the methyl methacrylate/meta-divinylbenzene pairs are comparable to those for related monomers ${ }^{15,28}$.

The monomer reactivity ratio data for the styrene/para-divinylbenzene pair cannot be so obviously correlated with the data for monovinyl pairs. The theoretically required intersect is not observed in plots of the differential data. Such data, based on low-yield copolymer analyses, show three or more intersects from copolymerizations at three different comonomer ratios (Figure 10) ${ }^{4,15}$. Approximations of the $r_{1}$ - and $r_{2}$-values can be obtained by eliminating the high para-divinyl copolymerization pairs (as the more likely to involve participation of the second vinyl group) or by a least squares

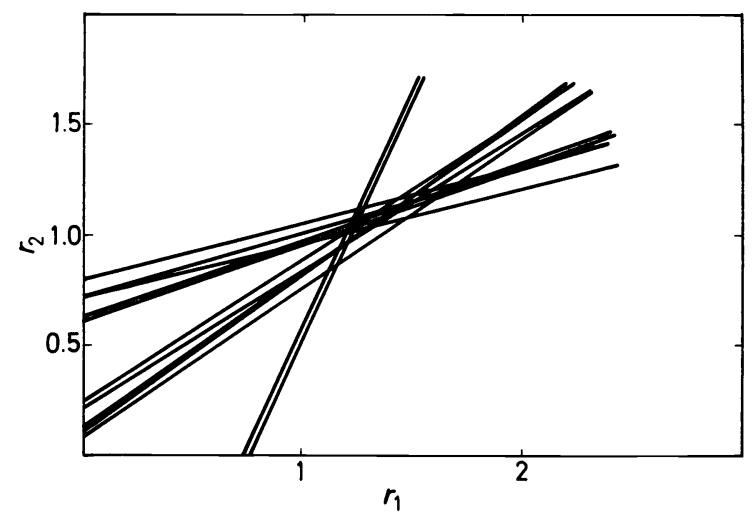

Figure 7. Intersect plot for the copolymerization of styrene $\left(r_{1}=1.27\right)$ and $m$-divinylbenzene $\left(r_{2}=1.08\right)$ at $80^{\circ} \mathrm{C}$ with benzoyl peroxide initiator. Conversion, $2.7-4.96 \%$ 


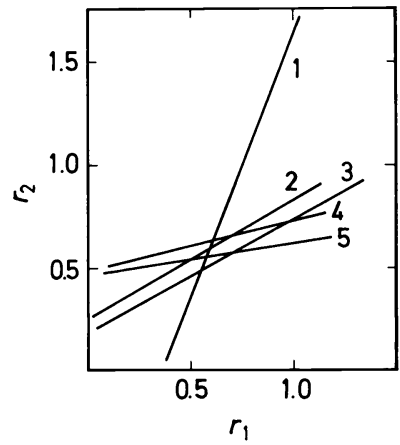

Figure 8. Intersect plot for the copolymerization of styrene $\left(r_{1}=0.65\right)$ with $m$-divinylbenzene $\left(r_{2}=0.60\right)$ at $60^{\circ} \mathrm{C}$ with benzoyl peroxide initiator. Direct counting assay.

analysis of the linear plot of the data. There is not very persuasive reasoning to support either approximation, but both give values $(0.15 / 0.5$ and $0.77 / 2.08)$ of the same relative magnitude; i.e. $r_{1}$ much lower than $r_{2}$. An $r_{1} r_{2}$ product greater than 1 argues against the validity of the linear least squares approximation. A similar situation is met in the methyl methacrylate/para-divinylbenzene data (Figure 11) ${ }^{28}$. Least squares analysis of the linear plot gives values of $0.1 / 0.93$ if all points are used or, if two highly erratic sets of data are discarded, $0.62 / 1.30$. This approach being somewhat less than satisfactory, attention was directed to use of the integral form of the copolymerization.

Using the integral form of the copolymerization equation and a Fortran II program developed by others ${ }^{37}$, high-conversion data for the styrene/paradivinylbenzene pair were analysed and compared with similar data for the styrene/meta-divinylbenzene pair $^{32}$. The latter gave values of $r_{1}=0.95-1.31$ and $r_{2}=1.00$ for the meta isomer (Tables 3,4). For the para isomer the values are $r_{1}=0.15-0.25$ and $r_{2}=1.00$. The integral meta values are thus in fairly reasonable accord with the differential values. Both sets of data indicate

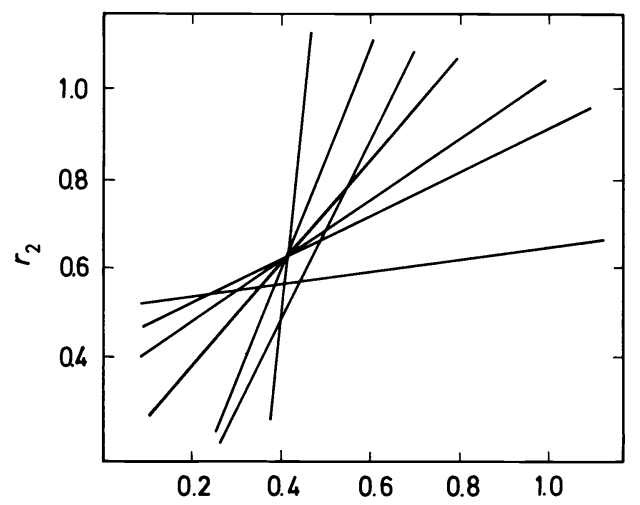

Figure 9. Intersect plot for the copolymerization of methyl methacrylate $\left(r_{1}=0.41\right)$ with $\mathrm{m}$ divinylbenzene $\left(r_{2}=0.61\right)$ at $70^{\circ} \mathrm{C}$ with benzoyl peroxide initiator 


\section{RICHARD H. WILEY}

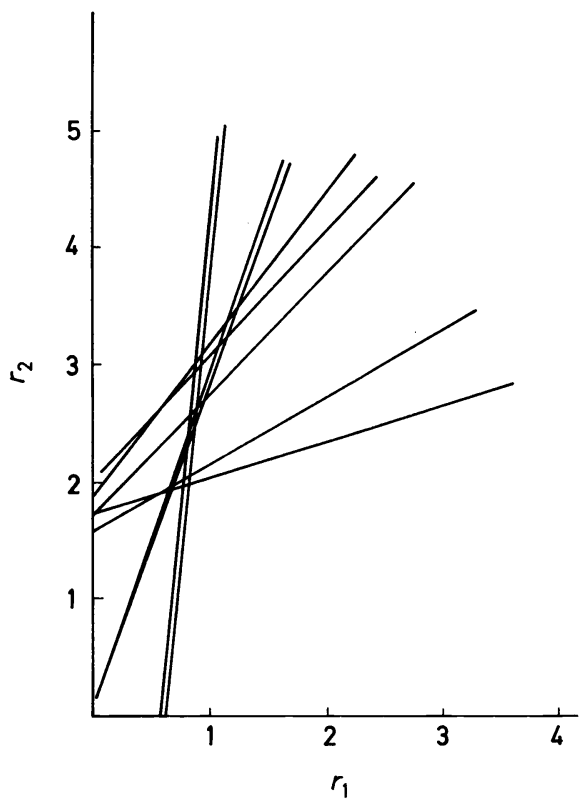

Figure 10. Intersect plot for the copolymerization of styrene $\left(r_{1}=0.77\right)$ and $p$-divinylbenzene $\left(r_{2}=2.08\right)$ at $80^{\circ} \mathrm{C}$ with benzoyl peroxide initiator

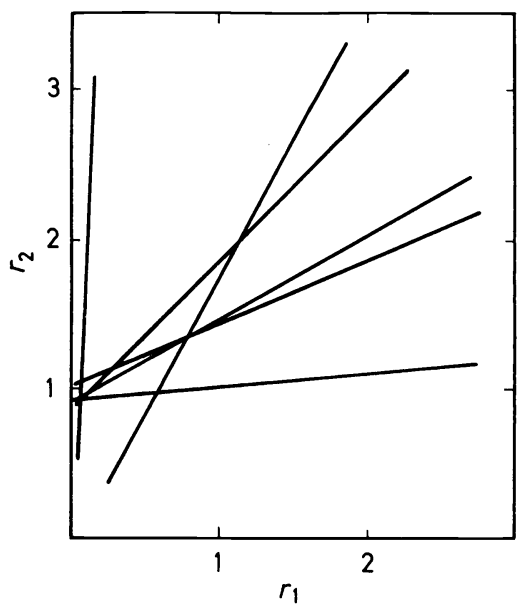

Figure 11. Intersect plot for the copolymerization of methyl methacrylate $\left(r_{1}=0.62\right)$ with $p$-divinylbenzene $\left(r_{2}=1.3\right)$ at $70^{\circ} \mathrm{C}$ and with benzoyl peroxide initiator. Values of $r_{1}$ and $r_{2}$ from least squares analysis of linear plot omitting the two extreme divergencies 
Table 3. Monomer reactivity ratios $\left(r_{1}\right.$ and $\left.r_{2}\right)$ for the styrene/m-divinylbenzene copolymerization

\begin{tabular}{cccc}
\hline Pairs & Av. conversion, $\%$ & $r_{1}{ }^{c}$ & $r_{2}{ }^{d}$ \\
\hline $1(4.7), 3(6.7)$ & 5.7 & 0.95 & 1.00 \\
1(4.7), 2(18.2) & 11.4 & 0.92 & 1.00 \\
$3(6.7), 2(18.2)$ & 12.4 & 1.08 & 1.00 \\
$1(4.7), 4(24.4)$ & 14.5 & 1.16 & 1.00 \\
$3(6.7), 4(24.4)$ & 15.5 & 1.31 & 1.00 \\
2(18.2), 4(24.4) & 21.3 & 1.29 & 1.00 \\
\hline
\end{tabular}

a Pairs of data points used, identified as experiment numbers in ref. 32 with the conversion in parentheses.

b Variation of these values by $\pm 10 \%$ gave $r_{1}$ values (top to bottom) of $0.912,0.920,1.077,1.157,1.314,1.292$, and $r_{2}$ values of 1.00 .

c Average, $r_{1}=1.11$.

d Average, $r_{2}=1.00$.

that for the styrene/meta pair the two monomers are essentially equivalent in reactivity towards the other radical with perhaps a slight alternating tendency. The data for the para isomer, although much less consistent, show a marked preference of styrene radical for para-divinylbenzene $\left(r_{1}\right.$ always significantly lower than $\left.r_{2}\right)$ and of para-divinylbenzene for itself $\left(r_{2}\right.$ above 1.0 and significantly greater than $r_{1}$ ).

Table 4. Monomer reactivity ratios $\left(r_{1}\right.$ and $\left.r_{2}\right)$ for the styrene/p-divinylbenzene copolymerization

\begin{tabular}{lccc}
\hline \multicolumn{1}{c}{ Pairs $^{a, b}$} & Av. conversion, $\%$ & $r_{1}{ }^{c}$ & $r_{2}{ }^{d}$ \\
\hline $6(1.93), 9(9.04)$ & 5.48 & 0.15 & 1.00 \\
$6(1.93), 8(14.89)$ & 8.41 & 0.25 & 1.01 \\
$6(1.93), 7(14.95)$ & 8.44 & 0.25 & 1.01 \\
$7(14.95), 9(9.04)$ & 11.99 & 0.18 & 1.00 \\
$7(14.95) .8(14.89)$ & 14.92 & 0.21 & 1.00 \\
\hline
\end{tabular}

a Pairs of data points used, identified as experiment numbers in ref. 32 with the conversion in parentheses.

$b$ Variation of these values by $\pm 10 \%$ gave $r_{1}$ values (top to bottom) of $0.149,0.182,0.268,0.178,0.209$, and $r_{2}$ values of 1.00 .

c Average, $r_{1}=0.20$.

A Average, $r_{2}=1.00$.

A structural implication is rather clearly established by these kinetic data. The para isomer polymerizes and copolymerizes more slowly than does the meta isomer. It is a monomer distinctly different from styrene. In copolymerization systems styrene and probably para-divinylbenzene prefer paradivinylbenzene, so that the para-divinylbenzene monomer will be rapidly exhausted from the polymerizing mixture. This suggests that, when the crosslinking stage is reached, the crosslinkages will be formed in bunches and probably some of the second vinyl groups will be buried and unavailable for crosslinkages. The picture is one of heterogeneities. The meta isomer, however, presents a picture of a more uniformly distributed divinyl unit with, ultimately, evenly spaced crosslinkages and a homogeneous network.

The question is now whether these widely different copolymerization characteristics will be reflected in differences in copolymer properties associated with presumably different networks. 


\section{CHARACTERISTICS OF THE STYRENE/META- AND PARA-DIVINYLBENZENE BEAD COPOLYMERS}

Bead copolymers of styrene and pure meta- or pure para-divinylbenzene were prepared by suspension copolymerization. Beads of $0.65-0.85 \mathrm{~mm}$ (20-30 mesh) and $125-250 \mu \mathrm{m}$ size were separated for the experiments. The larger beads were prepared with carboxymethylcellulose as the suspending agent. The smaller beads were prepared with a sulphated polyvinyl alcohol as suspending agent. Details of the copolymerization techniques and preparation of the sulphonated polyvinyl alcohol are given in the published reports ${ }^{1,23}$. The over-all size distribution observed in preparations of the smaller size beads is given in Figure 12. Yields of 70-90 per cent of beads of $125-250 \mu \mathrm{m}$ size were typical.

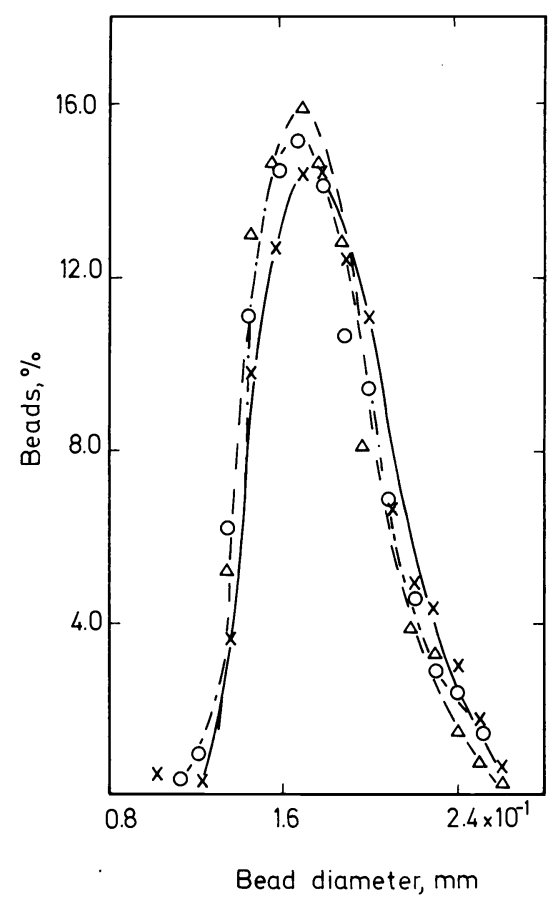

Figure 12. Size distribution curve of crosslinked bead copolymers of styrene with $4 \mathrm{~mol} \%$ of $\times$ commercial divinylbenzene, $\Delta m$-divinylbenzene and $O p$-divinylbenzene.

Rates of sulphonation were measured by titrating the increase in exchange capacity - for both size beads and with beads swollen in ethylene dichloride or dimethyl sulphoxide ${ }^{11,13,21,24}$. The fatter solvent gives a homogeneous medium for the sulphonation. Data for the rates are given in Figure 13. The rate is higher for the paja crosslinked structures and in dimethyl sulphoxide. It has also been noted that the rate of sulphonation for the copolymer crosslinked with a 2/1 meta/para mixture of divinylbenzenes is more rapid than that of pure isomer crosslinked copolymer (Figure 14). 


\section{CROSSLINKED S/DVB NETWORK SYSTEMS}

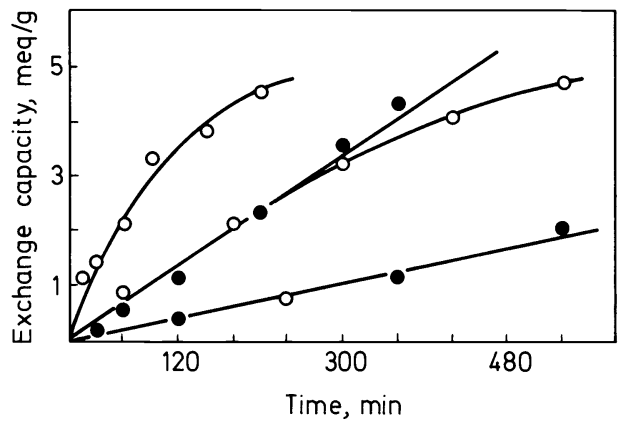

Figure 13. Sulphonation of bead copolymers of styrene with $8 \%$ pure $m$ - and pure $p$-divinylbenzene: $O$ in dimethyl sulphoxide; in ethylene dichloride. The upper pair of curves is for the para, the lower pair for the meta isomer

The structural conclusion consistent with these observations is that the sulphonating species, presumably sulphur trioxide $\left(\mathrm{SO}_{3}\right)$, is too large to penetrate the more uniformly crosslinked meta structure easily but has ready access to the long segments of polystyrene in the heterogeneously crosslinked para structure. In the early stages of the reaction in which the kinetic data are obtained, this distinction will be most pronounced.

Pyrolysis data for the meta- and para-divinylbenzene crosslinked copolymers of both styrene (Figure 15$)^{7}$ and methyl methacrylate (Figure 16) ${ }^{18}$

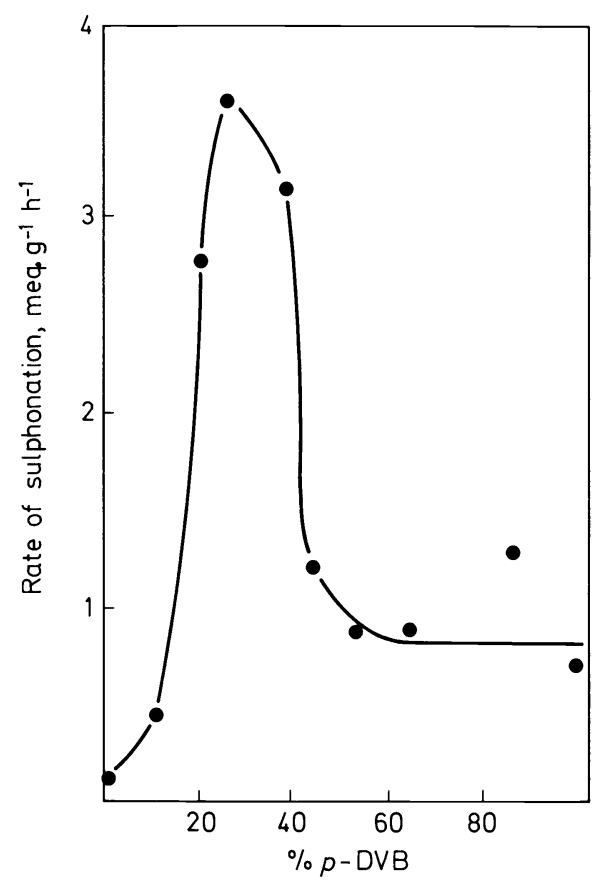

Figure 14. Rates of sulphonation, meq. $\mathrm{g}^{-1} \mathrm{~h}^{-1}$, of polystyrene crosslinked with $8 \%$ of varying mixture of meta- and para-divinylbenzene 


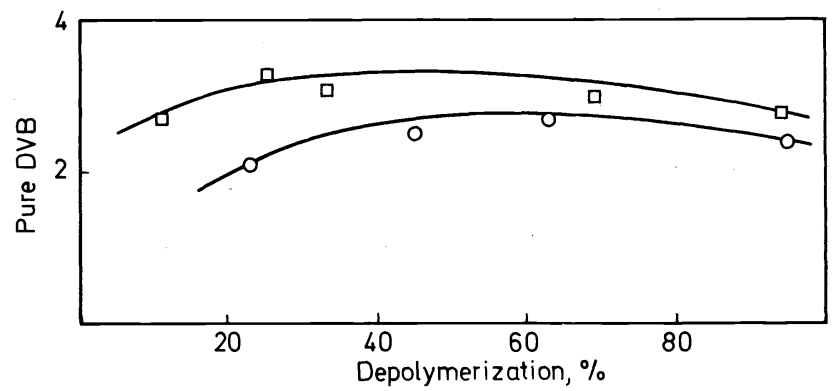

Figure 15. Rate of formation of pure divinylbenzene at $560^{\circ} \mathrm{C}$ from $\square 8 \% \mathrm{~m}$-divinylbenzene and from $08 \% p$-divinylbenzene styrene bead copolymers

show that the rate of appearance of meta-divinylbenzene, and the meta substituted products related to it, is higher than that for the para-divinylbenzene. This, also, is to be correlated with the presumed bunching of the para units in, in this case, less heat vulnerable positions. The data for the methyl methacrylate copolymers provide a more definitive picture presumably because the principal degradative process for the methacrylate structure

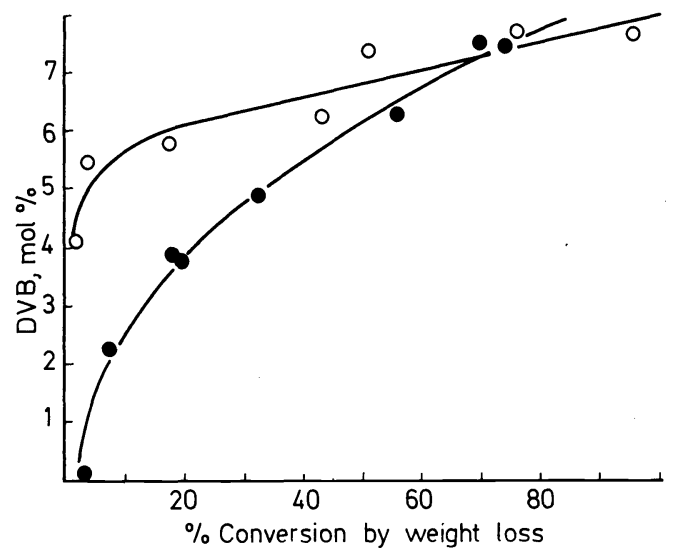

Figure 16. Rate of appearance of divinylbenzene-derived products in the pyrolysis at $552^{\circ} \mathrm{C}$ of $8 \%$ bead copolymers of $O m$-divinyl copolymers and of $p$-divinyl copolymers

is almost exclusively depolymerization. These data should correlate better with mass spectral data ${ }^{25}$ than has up to now been observed. There is a need for GLC/MS and TGA/MS data to provide additional information about these structural distinctions.

\section{CHARACTERISTICS OF THE SULPHONATED COPOLYMERS OF STYRENE/META- AND PARA-DIVINYLBENZENE}

Swelling ratios have been determined for the bead copolymers and the sulphonated copolymers ${ }^{1,19}$. These data are admittedly difficult to obtain 
with precision ${ }^{35}$, and the differences we have observed for the meta and para crosslinked types are not great. The maximum difference is about ten per cent for the one per cent crosslinked polymers (4.70 meta and 4.28 para) and sulphonated products (16.79 meta and 15.14 para). In all instances, however, the para crosslinked structures swell less than do the meta types. For the eight per cent divinyl copolymer beads, the ratios are 1.53 (para), 1.77 (meta) and $1.82(2 / 1$ meta/para). The data correlate with the rates of sulphonation: i.e. are in the same relative increasing order. Thus the para structure swells least and sulphonates least rapidly. The structural implications from these data are that the bunched para crosslinkages give a tighter, less solvent expandable network than does the uniformly distributed meta crosslinkage.

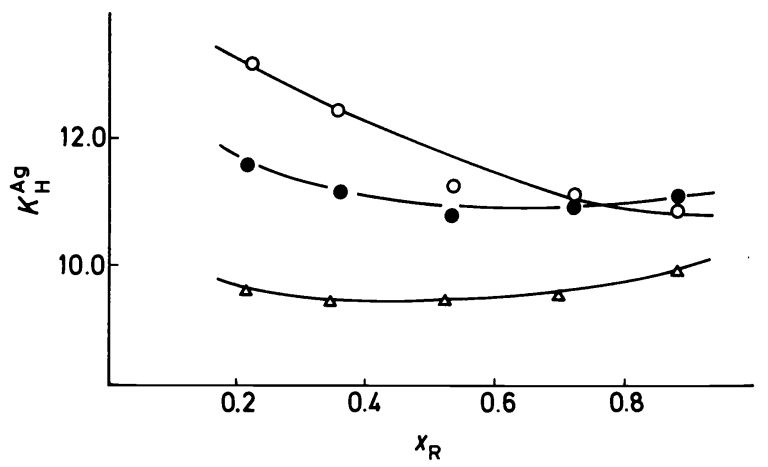

Figure 17. Silver-hydrogen exchange on $8 \%$ divinylbenzene crosslinked, sulphonated styrene bead copolymers: $O$ commercial divinylbenzene; $\bullet$-divinylbenzene; and $\Delta m$-divinylbenzene crosslinking

Equilibrium isotherms (selectivity coefficients) have been determined for the sulphonated copolymers ${ }^{34}$. The data for the sodium-, potassium-, rubidium-, caesium- and silver-hydrogen systems have been measured. Data for the other ions are similar-with lower values for $K$ and with less pronounced differences in the plots. There are significant affinity differences between the sulphonated eight per cent meta- and para-divinylbenzene crosslinked materials to be seen in these data. The value of $K_{\mathrm{H}}^{\mathrm{M}}$ for a given ion pair is clearly higher for the eight per cent para than for the eight per cent meta resin when the resins are predominantly in the hydrogen formbut an intersection of the meta and para curves occurs at $X_{\mathrm{R}}=0.65-0.8$ for all of the alkali metal (but not silver) systems. This meta-para difference in $K_{\mathrm{H}}^{\mathrm{M}}$ increases with increasing hydrated ionic radius of the metal ions. These differences are also seen to vary with the cationic composition $\left(X_{\mathrm{H}}^{\mathrm{R}}\right)$ of the resin, with a greater variation of $K_{\mathrm{H}}^{\mathrm{M}}$ for the para network. These effects are consistent with the concept that the para crosslinked network is the more heterogeneous (i.e. these effects are directly related to heterogeneity of exchange site) and with the greater impermeability of the meta crosslinked network to the larger of the reacting species-an effect observed in sulphonation reactions also. 


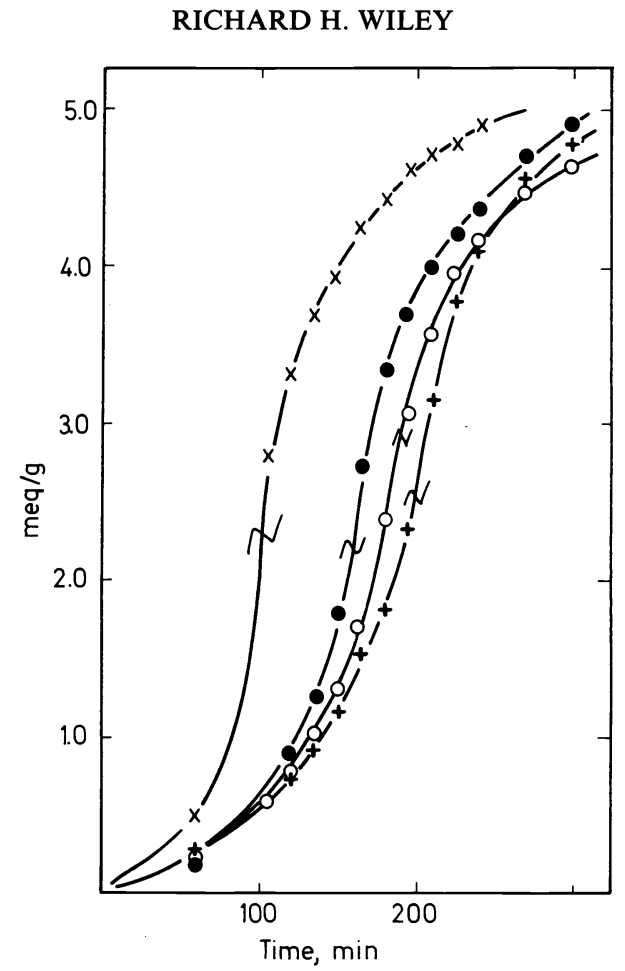

Figure 18. Rate of formation of acid in the peroxide-induced degradation of sulphonated styrenedivinylbenzene bead copolymers. Meq. of acid liberated per $\mathrm{g}$ of copolymer versus time. Inflection points indicated by break are taken from differential plots. +meta, para, O commercial divinylbenzene crosslinkage; $\dot{x}$ Resin-50W-8X

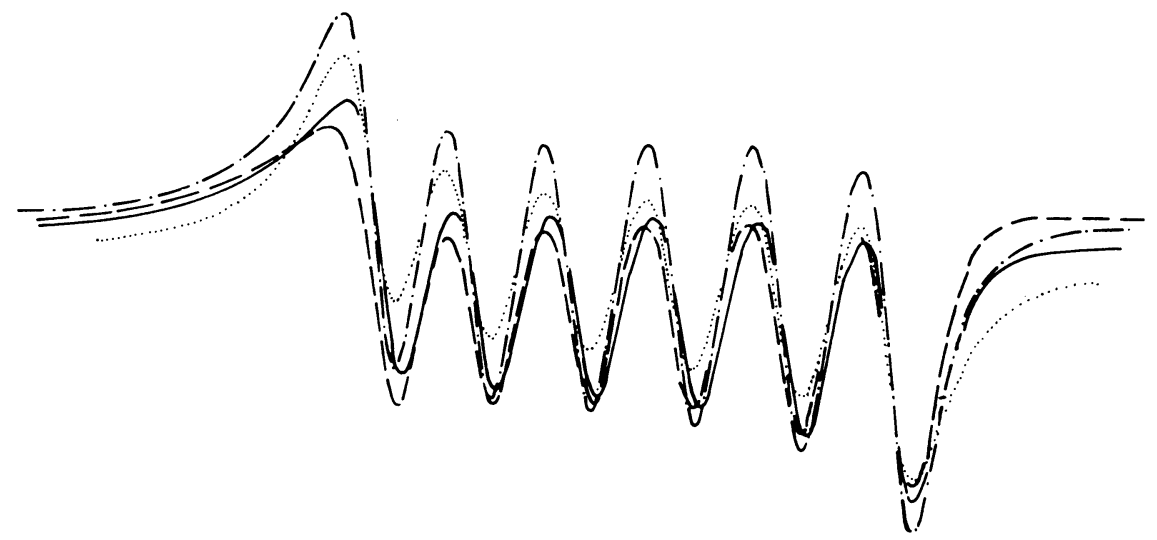

Figure 19. EPR spectra of $\mathrm{Mn}(\mathrm{II})$ on various ion exchange resins: sulphonated polystyrene crosslinked with $8 \%$ m-divinylbenzene $(--)$; with $8 \% p$-divinylbenzene (-); and with $8 \%$ commercial $(55 \%)$ divinylbenzene (-. - ) ; and for a commercial resin $(50 \mathrm{~W}-8 \mathrm{X})(\cdots)$. Scale divisions are $100 \mathrm{G}$. Readings of line widths and peak separations are given in ref. 31 . These samples were prepared by exchange of excess Mn(II) sulphate with the acid form of the resin 

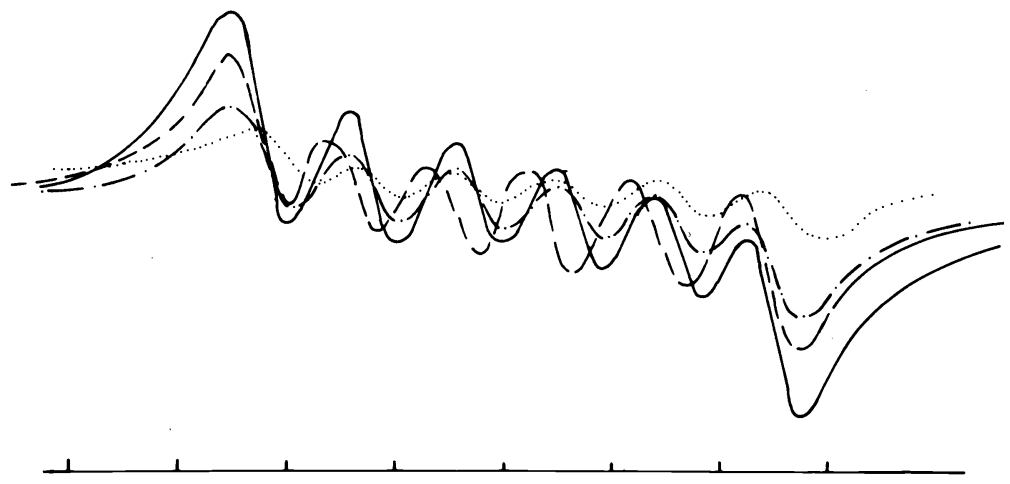

Figure 20. EPR spectra of $\mathrm{Mn}$ (II) on various ion exchange resins. The legend is the same as that for Figure 19. These samples were prepared by exchange of $c a$. one-half the equivalent amount of $\mathrm{Mn}$ (II) sulphate with the sodium form of the resins

The rate of degradation on treatment of the sulphonated copolymers with hydrogen peroxide is shown in Figure 18. The reaction is followed in terms of acid formation ${ }^{27}$. This reaction is thought to involve depolymerization because the beads dissolve during the course of the reaction; because the reaction is not induced by acid alone and is probably, therefore, not a simple desulphonation; and because the unsulphonated copolymers are not degraded by peroxide under comparable conditions. The para crosslinked structure degrades the more rapidly. From these data it is concluded that the acid is formed in a depolymerization which proceeds rapidly until a crosslinkage is reached-sooner with the meta than with the para network structure.

The electron paramagnetic resonance spectra have been observed ${ }^{31}$ (Figures 19-21) for the exchange of manganese(II) with sodium and hydro-

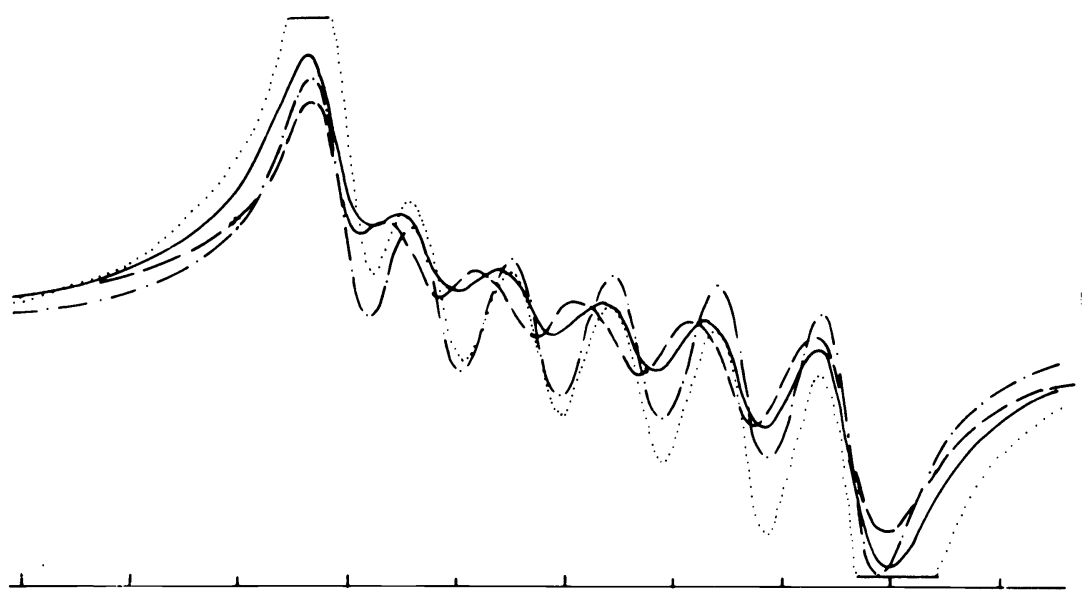

Figure 21. EPR spectra of $\mathrm{Mn}(\mathrm{II})$ on various ion exchange resins. The legend is the same as that for Figure 19. These samples were prepared by exchange of excess $\mathrm{Mn}$ (II) sulphate with the sodium form of the resins 
gen ions. The data show variations in hyperfine structure (HFS) intervals and line widths which distinguish the meta and para crosslinked networks. Line width broadening effects have been attributed to differences in ionic environments ${ }^{36}$. Ionic environemnts of different symmetry would be predicted for the differences in heterogeneity attributed to the resins. And, again, it is the para crosslinked network which shows the greater line broadening and, hence, greater heterogeneity of site. These site differences can be associated with inherent structural heterogeneities or with variable, and therefore also more heterogeneous, exchange of the large manganese(II) ion.

\section{CONCLUSIONS}

Network structural variations can be produced by selected synthetic procedures, and these can be related to controlled variations in properties. of the network. These conclusions are based on studies with copolymers of styrene with pure meta- and pure para-divinylbenzene in which the differences arise from differences in copolymerization characteristics. For these systems the differences are often subtle. Other networks ${ }^{1,6}$ with enhanced structural differences can be envisaged.

\section{ACKNOWLEDGEMENTS}

The author is indebted to the several postdoctoral assistants and doctoral candidates who have done much of the experimental work described herein. We are indebted to the Shell Development Co., Dow Chemical Co., Koppers Co., Cosden Petroleum Co. and Foster-Grant Co. for supplies of divinylbenzenes.

The research was supported in part by the University of Louisville, Hunter College and the Graduate Division of the City University of New York, and the Atomic Energy Commission.

Permission to reproduce figures from publications in the Journal of Macromolecular Science: Chemistry and from the Journal of Polymer Science is acknowledged with appreciation. In particular, Figures 1, 2, 3, 4, 6 and 9, and Tables 3 and 4, carry data previously published by Marcel Dekker Inc., while Tables 1 and 2 and Figures 5, 13, 14 and 18 were published by John Wiley \& Sons, Inc.

\section{REFERENCES}

${ }^{1}$ R. H. Wiley, J. K. Allen, S. P. Chang, K. E. Musselman and T. K. Venkatachalam, J. Phys. Chem. 68, 1776 (1964).

${ }^{2}$ R. H. Wiley and R. M. Dyer, J. Polymer Sci. A2, 2503 (1964).

${ }^{3}$ R. H. Wiley and P. H. Hobson, J. Amer. Chem. Soc. 71, 2429 (1949).

4 R. H. Wiley and E. E. Sale, J. Polymer Sci. 42, 491 (1960).

5 R. H. Wiley and B. Davis, J. Polymer Sci. 62, S132 (1962).

6 R. H. Wiley and G. L. Mayberry, J. Polymer Sci. A1, 217 (1963).

7 R. H. Wiley, G. DeVenuto and F. E. Martin, J. Macromol. Chem. 1, 137 (1966).

8 R. H. Wiley and T. H. Crawford, J. Polymer Sci. B3, 99 (1965).

9 R. H. Wiley and G. DeVenuto, J. Polymer Sci. A3, 1959 (1965).

10 R. H. Wiley and G. DeVenuto, J. Appl. Polymer Sci. 9, 2001 (1965).

11 R. H. Wiley and T. K. Venkatachalam, J. Polymer Sci. A3, 1063 (1965). 


\section{CROSSLINKED S/DVB NETWORK SYSTEMS}

12 R. H. Wiley and G. DeVenuto, J. Polymer Sci. A2, 5347 (1964).

13 R. H. Wiley and T. K. Venkatachalam, J. Polymer Sci. 4, 1892 (1966).

14 R. H. Wiley, G. DeVenuto and T. K. Venkatachalam, J. Gas Chromatography, 5, 590 (1967).

15 R. H. Wiley, W. K. Mathews, and K. F. O'Driscoll, J. Macromol. Sci.: Chem. A1, 503 (1967).

16 R. H. Wiley and T. K. Venkatachalam, Polymer Letters, 4, 981 (1966).

17 R. H. Wiley, G. DeVenuto and A. DeVenuto, J. Polymer Sci. 5, 1805 (1967).

18 R. H. Wiley and F. E. Martin, J. Macromol. Sci.: Chem. A1, 635 (1967).

19 R. H. Wiley and J. T. Badgett, J. Macromol. Sci.: Chem. A2, 103 (1968).

20 R. H. Wiley and T. Ahn, J. Polymer Sci. A1, 6, 1293 (1968).

21 R. H. Wiley, J. Jin and T. Ahn, J. Macromol. Sci: Chem. A2, 407 (1968).

22 R. H. Wiley and A. DeVenuto, J. Polymer Sci. A1, 6, 1501 (1968).

${ }^{23}$ R. H. Wiley, J. Jin and Y. Kamath, J. Polymer Sci. A1, 6, 1065 (1968).

${ }^{24}$ R. H. Wiley, T. Ahn and Y. Kamath, J. Polymer Sci. A1, 6, 1414 (1968).

25 R. H. Wiley and L. H. Smithson Jr, J. Macromol. Sci.: Chem. A2, 589 (1968).

${ }^{26}$ R. H. Wiley, J. Jin and T. Ahn, J. Macromol. Sci.: Chem. A3, 1543 (1969).

27 R. H. Wiley and E. Reich, J. Polymer Sci. A1, 6. 3174 (1968).

28 R. H. Wiley and J. Jin, J. Macromol. Sci.: Chem. A2, 1097 (1968).

29 R. H. Wiley and J. Jin, J. Macromol. Sci.: Chem. A3, 835 (1969).

30 R. H. Wiley, J. Polymer Sci. A1, 8, 792 (1970).

31 R. H. Wiley, J. Jin and E. Reich, J. Macromol. Sci.: Chem. A4, 341 (1970).

32 R. H. Wiley, C. P. Rao, J. Jin and K. Kim, J. Macromol. Sci.: Chem. A4, 1453 (1970).

33 R. H. Wiley, K. Kim, and S. P. Rao, J. Polymer Sci. A1, 9, 805 (1971).

34 R. H. Wiley and K. Kim, J. Macromol. Sci.: Chem. A8, 697 (1974).

35 D. H. Freeman, Anal. Chem. 39, 1141 (1967).

36 B. R. McGarvey, J. Phys. Chem. 61, 1232 (1957).

37 D. R. Montgomery and C. E. Fry, J. Polymer Sci. C, 24, 59 (1968). 